\title{
Algumas considerações sobre a consciência na perspectiva fenomenológica de Merleau-Ponty ${ }^{1}$
}

Ana Regina de Lima Moreira

Universidade Federal do Rio Grande do Norte

Resumo:

O presente estudo aborda, em caráter introdutório, a evolução do conceito de consciência na Filosofia Ocidental, especialmente na fenomenologia de Merleau-Ponty. Em quase toda a História da Filosofia, a consciência é considerada como uma função puramente intelectual, em oposição ao corpo, através da qual o homem pode alcançar o verdadeiro conhecimento. Merleau-Ponty apresenta uma nova concepção da consciência, na qual a realidade do cogito e a realidade corporal compõem uma unidade.

Palavras-chave: Consciência,

Corpo,

Fenomenologia.
Key-words: Conscience,

Body,

Phenomenology

\begin{abstract}
:
Notes on the concept of conscience in Merleau-Ponty's phenomenology. The paper is an introduction to the study of the concept of conscience in Western Philosophy, especially in the Merleau-Ponty's phenomenology. In almost the whole History of Philosophy, conscience is primarily taken as an intellectual function, with no bodily constitution, enabling human beings to achieve true knowledge. Merleau-Ponty proposes a new concept of conscience, in which the realities of cogito and the body are taken as an unit.
\end{abstract}


Breve reflexão sobre o conceito de consciência nos períodos antigo e medieval conceito de consciência foi abordado sob diferentes prismas ao longo da História da Filosofia. Na Antigüidade, o que existia era uma "consciência metafísica", desligada do mundo material, que buscava apreender a essência das coisas por meio da razão. Para os filósofos desse período, a consciência como intelecto é o que verdadeiramente define o homem. Este encontra-se dividido em corpo e mente, sendo o corpo a parte irracional e enganosa do ser humano.

Com o advento do cristianismo na Idade Média, a consciência adquire um caráter religioso e, ainda sob a perspectiva metafísica, ela pretende chegar à realidade íntima das coisas. Contudo, aqui, o que ela realmente quer alcançar é a natureza divina enquanto princípio da verdade e a quem a razão deve submeter-se. Permanece, portanto, a distinção e oposição entre consciência e corpo, sendo atribuído à primeira um papel primordial no processo de conhecimento.

É importante ressaltar que até a Idade Moderna, os filósofos compartilhavam o mesmo modo de pensar: o modo metafísico. Este consiste na crença de uma realidade autônoma e objetiva, independente do sujeito. As coisas existiam como realização de uma determinada essência, ou seja, "cada ser, cada indivíduo é do jeito que é porque, ao existir, ele está realizando uma essência, uma natureza que lhe define suas características específicas, ou seja, características pelas quais ele pertence a uma determina espécie de seres" (Severino, 1992, p. 77).

\section{$O$ advento da modernidade e a primazia do cogito}

O modo metafísico de apreensão da realidade foi analisado e criticado pelos filósofos modernos pois, para estes, o homem não pode chegar à essência das coisas através da razão natural. O que o homem pode efetivamente conhecer por meio daquela é o seu próprio pensamento ou atividade de consciência e o mundo fenomenal, isto é, as coisas tais quais se apresentam à nossa percepção. Desse modo, desenvolveu-se uma nova forma de representação do mundo, a saber, a ciência. 
Nessa linha de pensamento temos René Descartes, cuja Filosofia tem como princípio fundamental o seguinte: "Eu sou, eu existo, isto é certo, mas por quanto tempo? A saber, por todo o tempo que eu penso, pois poderia ocorrer que, se eu deixasse de pensar, eu deixaria de ser ou de existir" (Descartes apud Vergez \& Huisman, 1988, p. 151).

Observamos, então, que o "cogito ergo sum" ("penso, logo existo") constitui a auto-evidência existencial do pensamento, ou seja, a garantia de que o pensamento, como consciência, tem da sua própria existência. Todas as coisas que acontecem em nós, enquanto temos consciência delas (querer, imaginar, sentir etc.), é o mesmo que pensamento para Descartes (Abagnano, 1982).

O que diferencia Descartes dos filósofos dos períodos anteriores é o fato dele considerar todo o conhecimento como existente no próprio homem, um sujeito pensante, e não em algo exterior como Deus ou a natureza. Portanto, não precisamos sair do interior da nossa própria consciência para conhecer a verdade. Ao estabelecer uma linha divisória entre as realidades material e espiritual, Descartes é considerado um dualista e sua concepção de corpo caracteriza-se pelo mecanicismo. Assim, segundo Gaarder (1995), a res cogitans (substância pensante) é realmente a principal substância que define o homem, ela é consciência pura. Todavia, existe uma outra realidade no homem, totalmente distinta e independente daquela, a res extensa (substância corpórea). Esta ocupa lugar no espaço e não possui consciência.

Desse modo, a concepção cartesiana de corpo-máquina diz que o funcionamento do corpo está sujeito às leis do universo, seguindo, portanto, os princípios da Mecânica. O corpo se movimenta sem a ajuda da alma, ou seja, não há uma intencionalidade na ação humana (Nóbrega, 1995).

Observamos, claramente, que Descartes concebe o corpo como uma máquina, cuja existência independe totalmente da existência da alma ou consciência, apesar de considerar uma interação entre as realidades física e espiritual, que se dá por meio da glândula pineal presente no cérebro. Não resta dúvida, para Descartes, que a razão predomina sobre o sensível, prevalecendo, assim, o aspecto dualista do seu sistema filosófico. 
Assim como nos períodos anteriores da História da Filosofia, observamos na Modernidade uma restrição quanto ao uso do termo consciência, sendo esta considerada uma parte do ser humano, através da qual ele pode chegar à verdade e que valoriza apenas o intelecto em detrimento da nossa natureza sensível, ou seja, o corpo. Essa visão dualística do homem, presente no sistema de pensamento cartesiano, influenciou consideravelmente o pensamento ocidental em áreas diversas como a filosofia, a ciência e a educação.

O mundo contemporâneo e a relação corpo - consciência em Merleau-Ponty

Na Idade Contemporânea, surge o modo de pensar dialético, privilegiando a dimensão histórica da existência humana e atribuindo maior dinamicidade à consciência. Porém, embora seja dada maior ênfase ao conhecimento sensível, este permanece, para uma grande parte dos filósofos, sendo considerado inferior ao conhecimento racional. Nesse mesmo período, deparamo-nos com um grupo de pensadores que, insatisfeitos com as formas de conhecimento estabelecidas, resolvem criar uma nova metodologia para o conhecimento, tanto no âmbito da ciência como no da filosofia. Surge então, segundo Severino (1992), a Fenomenologia, tendo como intuito chegar às coisas mesmas, descrevendo os fenômenos tais quais eles são experienciados pela consciência e onde sujeito e objeto se interrelacionam no processo de conhecimento. O conhecimento do mundo, mesmo em termos científicos, se dá a partir da própria experiência do sujeito. Todo o saber científico deriva do mundo-vivido, ou seja, dos pensamentos, percepções e vivências que eu tenho no meio natural. Por isso, Merleau-Ponty (1994, p. 3) afirma que

tudo aquilo que sei do mundo, mesmo por ciência, eu sei a partir de visão minha ou de uma experiência do mundo, sem a qual os símbolos da ciência não poderiam dizer nada. O universo da ciência é construído sobre o mundo-vivido e, se queremos pensar a própria ciência com rigor, apreciar exatamente seu sentido e seu alcance, precisamos, primeiramente, despertar essa experiência do mundo da qual ela é a expressão segunda. 
É, pois, na intersubjetividade, ou seja, na intersecção das experiências entre os indivíduos, que o mundo fenomenológico encontra sentido (Merleau-Ponty, 1994).

Na perspectiva fenomenológica, a consciência adquire um novo significado, totalmente diferente daquele existente até então. Ela é definida como percepção, de modo que não há separação e oposição entre os dados sensível e racional no ato de apreensão das coisas. Nossas experiências constituem a fonte de todo o conhecimento, sendo este adquirido no próprio mundo, um mundo que existe ao nosso redor e que só passa a existir efetivamente para nós quando lhe atribuímos um sentido. O mundo está aí mesmo, ele é inesgotável, pois o conhecimento que podemos ter dele é em perspectiva, ou seja, há várias possibilidades ou ângulos de apreendê-lo, dependendo das nossas vivências. Sendo assim, a consciência está ininterruptamente voltando-se para o mundo e buscando, através da essência, um contato mais direto e profundo com a existência ou, em outros termos, com o próprio mundo. Essa intencionalidade, ou qualidade da consciência de dirigir-se ao mundo a fim de apreendê-lo, se manifesta na motricidade. É a motricidade que me permite lançar-me ao mundo e captar o seu sentido. Ela engloba tanto a significação intelectual (simbólica) como a significação motora, de modo que não há separação entre o dado sensível e o entendimento na apreensão que eu tenho do mundo. Sendo assim,

quando faço sinal para um amigo se aproximar, minha intenção não é um pensamento que eu preparava em mim mesmo, e não percebo o sinal em meu corpo. Faço sinal através do mundo, faço sinal ali onde se encontra meu amigo, a distância que me separa dele, seu consentimento ou sua recusa se lêem imediatamente em meu gesto. Não há uma percepção seguida de um movimento, a percepção e o movimento formam um sistema que se modifica como um todo. (Merleau-Ponty, 1994, p. 159-160)

É, pois, com o corpo que apreendo as coisas ao meu redor, de acordo com as situações que vivencio. Minha presença no mundo é, portanto, uma presença corporal. Estamos, contudo, nos referindo aqui 
não à noção cartesiana de corpo, o corpo-máquina, mas ao corpovivo ou corpo-próprio, dotado de intenção e onde residem nossas ações originais. A experiência do corpo-próprio revela-nos um modo de existência ambíguo. Não podemos decompor e recompor para formar dele uma idéia. Por isso, ele não é um objeto, e a consciência que tenho dele não é um pensamento.

O modo como meu corpo se encontra no mundo é expresso pelo esquema corporal. Essa presença corporal define o lugar de onde vivenciamos o mundo, isto é, a zona de corporeidade. É habitando o espaço e o tempo que minhas ações adquirem um sentido que é atribuído pela corporeidade. A mesma funda-se no corpo-próprio ou corpo-vivo dotado de uma intencionalidade original, ou seja, de motricidade, a qual me permite voltar-me ao mundo para apreender o seu sentido.

É como ser sexuado que o corpo realiza a existência, isto é, nossos gestos possuem uma significação que é sexual. Contudo, a sexualidade aqui não se limita à genitalidade, mas revela a nossa maneira de ser. Dentre os gestos que o corpo exprime, encontra-se a fala como estando totalmente enlaçada ao pensamento. A fala é, pois, dotada de um sentido afetivo que permeia a relação com o outro, numa reciprocidade de intenções.

É, pois, pela linguagem sensível que o corpo-próprio expressa a unidade do homem. O sensível refere-se ao domínio pré-objetivo, o do sentir, ao mundo sobre o qual repousa todo o conhecimento objetivo, sendo também aquilo que nos confere uma existência singular.

Torna-se claro, portanto, que Merleau-Ponty não considera a existência de uma rígida divisão e oposição entre a consciência e o corpo, como no cartesianismo, pois ambos estão dialeticamente relacionados, haja vista a qualidade do corpo de expressar, numa linguagem sensível, a unidade humana.

\section{Referências}

Abagnano, N. (1982). Dicionário de Filosofia. São Paulo: Mestre Jou.

Gaarder, J. (1995). O Mundo de Sofia: romance da história da filosofia. São Paulo: Companhia das Letras. 
Merleau-Ponty, M. (1994). Fenomenologia da Percepção. São Paulo: Martins Fontes.

Nóbrega, T. P. (1995). Aprendendo com o corpo: pressupostos filosóficos da corporiedade na educação física. Dissertação de mestrado, não publicada. Universidade Federal do Rio Grande do Norte, Natal, RN.

Severino, A. J. (1992). Filosofia. São Paulo: Cortez.

Vergez, A., \& Huisman, D. (1988). História dos filósofos ilustrada pelos textos. Rio de Janeiro: Freitas Bastos.

Ana Regina de Lima Moreira é psicóloga e psicoterapeuta. Especialista em Consciência Corporal e em Psicologia pela Universidade Federal do Rio Grande do Norte. Endereço para correspondência: Rua Mipibú, 342, Petrópolis, 59020-250, Natal, RN.

\footnotetext{
Nota ${ }^{1}$ Resumo da monografia apresentada ao término do Curso de Especialização em Consciência Corporal (março de 1996), na Universidade Federal do Rio Grande do Norte, sob a orientação da Prof ${ }^{\mathrm{a}}$. Ms. Terezinha Petrúcia da Nóbrega.
}

Sobre o autor 